Article

\title{
Smart Cities in Russia: Current Situation and Insights for Future Development
}

\author{
Artem Yuloskov ${ }^{1}$, Mohammad Reza Bahrami ${ }^{2, *}$, Manuel Mazzara ${ }^{1}\left[\right.$ and Iouri Kotorov ${ }^{3}$ \\ 1 Institute of Software Development and Engineering, Innopolis University, 420500 Innopolis, Russia; \\ a.yuloskov@innopolis.university (A.Y.); m.mazzara@innopolis.ru (M.M.) \\ 2 Institute of Information Security and Cyber-Physical Systems, Innopolis University, 420500 Innopolis, Russia \\ 3 Department of International Business, North Karelia University of Applied Sciences, Karjalankatu 3, \\ 80200 Joensuu, Finland; Iouri.Kotorov@karelia.fi \\ * Correspondence: mo.bahrami@innopolis.ru
}

check for updates

Citation: Yuloskov, A.; Bahrami, M.R.; Mazzara, M.; Kotorov, I. Smart Cities in Russia: Current Situation and Insights for Future Development. Future Internet 2021, 13, 252. https:// doi.org/10.3390/fi13100252

Academic Editors: Söbah Abbas Petersen, Armin Shams, Amir Sinaeepourfard and Bokolo Anthony Jnr.

Received: 27 August 2021

Accepted: 23 September 2021

Published: 28 September 2021

Publisher's Note: MDPI stays neutral with regard to jurisdictional claims in published maps and institutional affiliations.

Copyright: (C) 2021 by the authors. Licensee MDPI, Basel, Switzerland. This article is an open access article distributed under the terms and conditions of the Creative Commons Attribution (CC BY) license (https:/ / creativecommons.org/licenses/by/ $4.0 /)$.

\begin{abstract}
The development of smart cities is a clear growing trend all around the world. The convergence of different technological, social, political, economical, and ecological trends has allowed the concepts to rise up quickly in governmental agendas. In this paper, we analyze the situation of Russia regarding smart cities. Moscow, Saint Petersburg, and Kazan are considered at the "Smart City 3.0" stage of development, meaning that the citizens are participating in their advancement. Our reasons to focus on Russia are two-fold: (1) we know the situation well, as we live and work in a new city, Innopolis, founded in 2015 and meant to be a blueprint for smart cities; (2) large Russian cities are actively developing projects in this sphere and are highly regarded worldwide in these endeavors. It is therefore worth analyzing the context and the trends. By studying the scientific literature and categorizing the features of smart cities the world over, we found that large Russian cities are developing most of the components necessary in order to be called smart. Herein we also discuss areas of possible growth for Russian cities, such as green technologies and a smart environment.
\end{abstract}

Keywords: smart city; smart city components; smart cities in Russia; challenges for smart cities in Russia

\section{Introduction}

According to the United Nations Report [1], in the 2014 revision, the word will face an increase in the urban population of $68 \%$ by 2050 (this number was $55 \%$ in 2014). It is undeniable that urbanization has a significant adverse effect on the quality of life of people, making the development of urban infrastructure an absolute necessity. Cities are complex systems in which many different stakeholders interact [2]. The time has come to start thinking about smart cities_cities in which many processes are automated and intelligent, resources are allocated, and existence is sustainable. Social sustainability, environmental sustainability, and economic sustainability are three major pillars of the concept of a smart city [3]. However, it should be noted that the three pillars of a smart city do not imply any standard solution or one-size-fits-all model to be subsequently rolled-out world-wide. Indeed, as argued by A. Cocchia, "The smart city concept has not yet been uniformly determined but is interpreted differently depending on the focus area" [4].

Large Russian cities are actively developing projects in the spheres of health protection, education, waste disposal, information collection, and monitoring [5]. Moscow, Saint Petersburg, and Kazan are considered at the "Smart City 3.0" [6] stage of development. This means that the citizens are participating in the innovation. Small Russian cities have the opportunity to build such smart city infrastructure from scratch. Smart transport and security systems, education, and healthcare smart services are going to be built in the coming decades in many Russian cities.

Russia is a particularly interesting case study for smart cities, since a large portion of the population is concentrated in large urban areas, and only a small part in the vast rural 
regions. Therefore, any innovation related to smart cities would immediately affect most of the citizens, and so can be tested. For example, in European Russia 70\% of population live in $20 \%$ of the territory, primarily Moscow (14\% of overall population), Saint Petersburg (7\%), Yekaterinburg, Kazan, etc. (https: / / rosstat.gov.ru/ accessed on 22 September 2021).

An ideal smart city is a place comfortable for people, green, clean, cozy, and quiet. There is still no universally accepted definition of the term "smart city". Various definitions draw attention to different facets of this term. According to Vidiasova et al. [7], a comfortable and safe environment that is constructed with the help of computerized technology is called a smart city. Another definition of "smart city" presented in the article [8] mentions that the "smart city" is a new kind of urban environment that provides sustainable growth and stimulating high-tech economic activity, which reduces the burden on the environment and improves the populations' quality of life. Instead of focusing on defining the term, let us see what it means for a citizen to live in a smart city.

We characterize smart cities by describing the day of a single young professional in Section 2. We need a framework in order to understand and talk about smart cities. In Section 4, we introduce the common components for smart cities around the world. Then, in Section 5, we discuss Russian cities in terms of certain "smart" characteristics. Challenges for smart cities are discussed in Section 6.

\section{How Life Will Be in Smart Cities}

Cities should focus on providing comfortable conditions for their citizens via the use of computer technology. Subsystems and subsystems of subsystems should work together in a synchronized cluster to make life easier and as personalized as possible. Terabytes of data will be processed every second to know each citizen's preferences. The city, consisting of technological products from different vendors, will know its citizens better than they know themselves. In this section, we will describe an ideal day for a single young professional in a smart city of the future.

Demyan-Landulf Damilola Karpov (the name is from the book "S.N.U.F.F" by Viktor Pelevin; just Damilola for friends) smoothly wakes up at the perfect time for him. His voice assistant chooses the time based on Damilola's biorhythms. Soft music is already playing and the curtains are opened; information on weather and traffic conditions is delivered. Damilola looks at the ceiling and the projection on it shows 7:56 AM, 25 January 2042. He asks the voice assistant about the schedule for today and orders it to warm up the electric car (the winters are still cold in the future). He decides not to use car-sharing todaythe feeling of driving a car is still pleasant, especially when the roads are smooth. Then Damilola takes a shower; the temperature is perfect, but he wants to feel refreshed-simple voice command makes the water colder.

The breakfast is delivered to them on the doorstep by a small intelligent robot in accordance with the daily habit of the user and without the need for a specific order. After that, Damilola goes to the office using their electric autonomous vehicle. Damilola's job is related to IT (information technology) projects. He spends significant time sitting in front of a screen. The chair adjusts its position accordingly, and the screen reminds im when it is time to avert their eyes and stretch their legs. When the lunch break comes, Damilola decides to eat at the canteen. The smart food recognition system allows them to pay for the food without stopping in the line (possibly via biometric or face recognition); the cost is debited from their account automatically. Till the end of the working day, he works on the elimination of annoying bugs in a neural network used for image recognition. Damilola wants to meet with their friends in the evening. They want to go to the theater (some things do not change). On their way to the car, Damilola sees an incorrectly parked vehicle. It is in the way of pedestrians. As a responsible citizen, he reports the problem to the government service "citizen-freedom.gov". Feeling proud, Damilola says to their assistant that he is ready to go to the theater. The assistant sends notifications to their friends, and after several minutes, he gets the responses with confirmation. Damilola takes their car and asks to go to the theater. From Damilola's schedule, the AI (artificial intelligence) in the car understands 
the destination and slowly starts to drive. The vehicles can communicate with each other, so there are no signs or traffic lights on the road. If car needs maintenance, this will be directly communicated to the service-center, unless owner intervention is needed. The car may also need further instructions, and thereby interact with the driver.

The ride is smooth, as always. Via a system of smart-parking, the parking slot is already reserved automatically when Damilola arrives at the theater. Together with friends, he gets to the theatre main hall. There are no cashiers at the entrance; the face recognition system automatically let the company in. Damilola places their coat in the wardrobe and looks at their smartphone. On the screen, he has the guide on how to find their seat and the program of the evening. The production reinterprets the classical "First Contact with the Martians" in a meta-modern style. After the performance, Damilola and friends go to a restaurant; the place was already booked by the personal assistant. Scrolling through the digital menu, Damilola got the recommendations based on their health and personal tastes.

After the meal, Damilola goes home. The home was automatically warmed up. When he arrives, his favorite song is playing and the light is on. Damilola falls asleep after reading several chapters of a book the AI recommended to him.

\section{Related Work}

There were many attempts to address the challenges of smart cities and to standardize the definition of the term "smart city" itself $[7,9,10]$. In [10], some important features, such as "smart environment", "smart management", "smart mobility", "smart economy", and "smart people" were discussed. Additionally, they reviewed the infrastructure essential for a smart city. However, they did not address the challenges for smart cities in their work.

The authors of [11] conducted a general review of the existence of the smart cities in different countries. They also addressed the challenges and highlighted opportunities for smart cities in terms of smart community, smart transportation, smart healthcare, smart energy, integration, and inter-operation.

Several studies $[9,12]$ described the process of the formalization of the smart city concept. They mostly focused on international practice in standardization. D. Namiot and M. Sneps-Sneppe [12] suggested utilizing the BSI (British Standards Institution) [13] standards for Russian smart cities. However, in Russia, a formalized form of the "smart cities" concept is approved and is being implemented as a departmental project of the Russian Ministry of Construction called "Smart City". This approach should solve a multifaceted range of tasks: competitiveness, efficiency, safety, comfort, technology effectiveness, and human orientation [14].

The development of smart cities is directly connected with the development of intelligent transportation systems, which represent a key enabler for their development. The increasing load on the roads could be managed by the use of sensor-based systems for the detection or the prediction of road pavement conditions. Vehicle-to-vehicle and vehicle-toinfrastructure communication are research areas related to IoT applications [15-17].

\section{Smart City Components}

Most authors agree that a smart city should have some form of smart transport management. This includes the usage of sensors for public transport, and algorithms for traffic management, and smart navigation.

A smart community is a concept about the residents of a smart city and the social connections between them. This term is also common in the literature. V. Mishchenko et al. [10], explained that people in a smart city should be educated to be capable of using technology. The authors suggested that creativity and high intellect of residents imperative for a smart city environment, as is residents' will to work to in such an environment. In [11] the authors did not make assumptions about people's characteristics, as opposed to the article [10]. They mostly focused on the behavior of the residents. For example, they suggested that any smart community should contain smart waste management systems as well. 
The components of a smart city may vary. However, the following subsections discuss essential components of any smart city [10,11].

\subsection{Smart Transport}

A smart city should include a transport management system that can cope with the increasing load on the roads. Three main parts of a smart city transport system are dynamic traffic assignment, green energy transport, and smart public transport.

1. Dynamic traffic assignment: Traffic is managed in a network by dynamic traffic assignment measurements via detection, communication, information provision, and real-time control. Several algorithms have been suggested for smart traffic management $[18,19]$. They allow making individual route decisions based on the current road situation. Additionally, such algorithms can monitor the traffic and gather data for future use. However, these algorithms are still computationally demanding, as they require processing a lot of incoming data. Another approach is to dynamically regulate the traffic lights. In work [20], authors described how wireless sensor networks (WSN) and multiple fuzzy logic controllers can be used to make a system for smart traffic light management [20]. Parking space is managed via smart-parking systems [21,22].

2. Green energy transport: Green energy transport should be a part of the smart city transport system. Governments the world over are taking measures to promote electric transport. An assessment of promotion measures in China can be found in the article [23]. Public transport is easier to switch to green energy than private because it is controlled by the government. However, this transition can be quite expensive.

3. Smart public transport: Public transport in modern cities has been growing in the last few decades. It is environmentally friendly, can carry more people, and is cheaper. In a smart city, public transport must meet certain criteria. Here are some of them:

- $\quad$ Electronic payment speeds up the passenger flow and can be more convenient for people.

- $\quad$ Tracking and load balancing systems can track accidents on the road, detect unexpected delays, and measure the efficiency of the transport system [18]. Decisions about public transport stops and routes can be made based on this data.

- $\quad$ Self-driving buses are expected to become a major part of the public transport system of most smart cities. According to V. Nagy and B. Horvath [24], public transport and private transport will be enhanced by the appearance of selfdriving vehicles. The authors claimed that the usage of unmanned public buses may result in decreased usage of personal vehicles and a decrease in the number of drivers. However, this research was conducted in Hungary, and it is not clear how well that generalizes to other countries.

\subsection{Smart Communication}

Good communication between the people and the city government makes a city a better place to live. The problems are solved faster and citizens get a better environment as a result. There are several ways to enhance communication in the city.

1. Government portals: The government should provide certain services for its citizens. Such services include creating a safe environment for the mind and body and issuing various documents and certificates. To get some particular document, one often has to visit a government agency several times. In a smart city, this problem has to be solved using information technology. Allocation of papers should happen remotely and automatically. Another common problem is tax payments. In the smart city, a tax payment should be as convenient as possible. This can be solved by digitalizing the entire process. For example, there is a UK government portal which helps to manage taxes [25].

2. City problem trackers: Many problems arise in daily life in a cityL road accidents, fires, power outages, and so on. In a smart city, citizens should be able to easily 
track such problems. That could be done via the centralized governmental source of information. The aim of this source should be to provide relevant and accurate information. In this way, citizens will be able to make adjustments to their plans according to the state of the problems.

3. Emergency notifications: A system for notifications about earthquakes, fires, floods, and other natural disasters could be implemented with the use of information technology. For example, in the article [26] the authors proposed an application (android base) which can send warning alarms to people via SMS or voice call before cyclones and floods strike, or other types of natural disasters, and also can tell them about the optimal routes to the nearest shelter. Another possible solution is to use Bluetooth technology to pass instructions between people. That can be helpful if the communication systems may be disabled. The use of such systems can make the city a safer place for people.

\subsection{Smart Services}

Cities provide various services for their citizens. Such services can include cleaning of the streets, police, healthcare, education, housing, and communal services. These services are essential for city life. This section focuses on describing some of the mentioned services in a smart city.

1. Smart healthcare: Many approaches exist to increase the operational convenience of hospitals. For example, in the article [27], the authors proposed an IoT-aware smart hospital system with the purpose of automatically monitoring and tracking personnel, patients, and biomedical devices inside hospitals. These systems are meant to reduce costs and increase the quality of service. Connecting hospitals to the smart communication system gives another vector of development for the smart city. However, healthcare is not only about the hospitals. Technology can improve many aspects of modern city healthcare. For example, personalized recommendations on food, exercises, and even vacation trips could improve health. Furthermore, remote control of key characteristics such as pulse, temperature, and unexpected falls could help to reduce the risk of injuries and serious consequences for health.

2. Smart education: According to the article [28], the focus of smart education is seamless learning aimed at promoting learners' intelligence. This concept facilitates students' problem-solving ability in smart environments. The use of video conferencing, progress tracking apps, and individual recommendations based on AI can improve education quality. However, making all these services work together is a challenge.

3. Smart security: Security in a smart city is mainly associated with the network of video surveillance cameras. The use of such systems together with modern AI technologies can predict and prevent crimes [29], and detect criminals in a crowd. Furthermore, such systems can manage access to restricted territories. Security systems process a lot of personal data. Additionally, storing such data securely should be a prime concern for software vendors. Furthermore, automatic processing of personal data raises ethical questions. Should we track a person's movements? Can we record the meetings of people? As a society, we should answer these and other questions which smart security systems raise.

\subsection{Smart Environment}

The environment is everything that surrounds the citizens daily. In a smart city, the environment should be interactive (in terms of information technology). Furthermore, it should increase the citizen's quality of life. A smart environment is the composition of the following factors.

1. Smart buildings: Buildings are a key component of any city. In a smart city, buildings should be energy efficient and secure. Security includes monitoring the building's energy state and fire control system, as well as personality identification at the entrance. 
Energy efficiency can be achieved via the energy-saving design of the building and the use of renewable sources of energy, such as solar panels [30].

2. Smart waste sorting: Waste management is an essential part of a city's infrastructure. The growing human impact on the environment has made governments take measures to reduce harmful effects. One of the problems with waste sorting is inattentive or uninformed citizens who do not practice waste sorting. This makes the process harder, as the waste must be sorted by professionals as well. L.-p. Zhang and Z.-p. Zhu [31] discussed the problem of waste management in China. They investigated the impact of smart bins on people's behavior and came to the conclusion that smart trash bins can assist in imposing some external pressure on residents who do not follow waste sorting regulations while also offering some financial benefits for those who do.

3. Charging stations: The growing role of electric devices such as smartphones imposes on the city environment certain obligations. Mobile charging stations can be quite convenient for citizens and also affect the city's economy. The lack of charging stations for electric cars is a stopping factor in buying one for some people. Therefore, it is important to have a system of charging stations for electric cars.

4. Interactivity: The environment of the city should be interactive in terms of information technologies. Informational QR-codes, interactive public transport schedules on the bus stops, free internet access points, and audio guides through the landmarks of the city are examples of such interactivity. These features could increase the tourist potential and convenience for the city's residents.

\section{Russian Cities in Terms of the Proposed Decomposition}

Russian cities are heterogeneous in terms of the suggested components. Some cities, such as Moscow, Kazan, and Saint Petersburg, implement most of them. In other cities, only a few of these features occur. Here is the review of some cities implementing the proposed components.

\subsection{Smart Transport}

There were successful experiments in the dynamic regulation of traffic lights. For example, in Voronezh, 140 traffic lights decreased the time to pass the crossroads by $18 \%$ [32]. Such experiments are going to continue in the future.

Public transport systems in Russia are actively developing. Most of the major cities already have electronic payment and tracking systems.

There are attempts to make public transport green. For example, as of 2020, 475 electric buses are operating in Moscow. Although the use of electric buses is an arguable solution, the trend for green public transport exists.

\subsection{Smart Communication}

All citizens of Russia have access to the unified portal of public services called Gosuslugi [33]. This portal provides the capability of remotely issuing documents, fines payment, making an appointment with a doctor, etc.

Another form of smart communication that is currently implemented in Russia is SMS notifications about emergencies and bad weather conditions.

Moreover, in some cities have portals for reporting problems with services, roads, etc. Such cities include Moscow [34], Kazan [35], and some others.

\subsection{Smart Services}

Smart education in Russia is actively developing. The use of video conferencing technologies and grade/homework tracking applications has become standard today in major cities. Schools all over the country use information technology to enhance communication between students and teachers.

Smart education and healthcare in Russia have received a new impetus to develop due to the epidemiological situation in the world [36]. Electronic classes using videoconfer- 
encing have become a new reality for schoolchildren and students all over the country, and electronic appointments with doctors have become a key form of healthcare.

Smart video surveillance systems are used in Moscow. They can detect criminals in the crowd based on their images in the police database. Such systems are planned to be distributed in other major cities.

\subsection{Smart Environment}

Many buildings in Russia include fire detection systems. For some categories of buildings, such systems are enforced by law [37]. Furthermore, many public buildings require personal identification at the entrance. Usually, it is achieved via the use of electronic cards. Residential buildings are often equipped with entrance protection systems (intercom systems; fingerprint recognition systems).

\subsection{Smart Agriculture}

Food equality, quality, affordability, and availability are the starting points of smart agriculture. Smart farming is measuring different parameters of plants and fields using sensors and helping farmers to make decisions and to stop pests, diseases, etc. [38]. Precision agriculture, as part of smart agriculture, involves the placement of sensors in plants to achieve targeted measurements and deploy targeted care mechanisms. This will be necessary for future food security [39].

\section{Challenges for Smart Cities in Russia}

Russian cities have mostly developed a smart communication component, but other components are not that common. Here is a review of components that are yet to be developed and the potential challenges that might be faced.

\subsection{Public Transport}

One of the challenges in creating a good public transport network in Russia is its climate. Operating smart public transport in winter is not an easy task. Mainly, this is due to low temperatures and a lot of snow. Regarding autonomous public transport, weather conditions play a big role in the quality of autonomous driving. Another issue is the high usage of personal vehicles in Russian cities. Personal vehicles congest roads and slow down public transport. In the Moscow region there are currently more than seven million vehicles. The amount of automobiles in Moscow has grown fivefold since 1990 (https:/ / tass.com/society/981132 accessed on 22 September 2021). To motivate people to use public transport and therefore reduce road congestion, a smart policy of taxes and regulations should be used.

\subsection{Smart Environment}

Waste sorting is a big problem in Russian cities. There is almost no infrastructure for separate garbage collection [40]. This problem should be addressed by local governments, and there are attempts underway to introduce waste sorting in the government buildings. One of the main challenges in introducing such a system in a city is public education. It is hard to make an efficient waste sorting system without the proper attitude from citizens. A potential solution could be the use of the previously mentioned smart bins or/and the introduction of taxes and regulation policies.

Another problem is the lack of charging stations for electric cars. It slows down the development of green transport.

\subsection{Interoperability}

One of the problems that should be solved in smart cities is interoperability. Many subsystems operate together in the city, and they should work coherently to provide a smooth experience for people. This challenge is common for all smart cities, and several architectural suggestions potentially could solve it. For example, in the article [41], the 
authors suggested using a modular architecture to assure coherence between various subsystems. In Russia, this problem is not that critical, as the technologies that operate in the cities are often controlled by the government. Thus, agreeing on some common interfaces is easier than it would be if the software was controlled by third parties.

\subsection{Public Awareness}

Public awareness of the systems used is critical for the successful functioning of the city. For example, the sorting of household waste is almost impossible without a careful attitude of citizens to it. The same applies to the use of green technologies. Public awareness is one of the biggest problems for smart cities in Russia. The solution to it could be government regulations or tax-cutting for crucial technologies. Another possible way is advertisement campaigns promoting the use of smart city features.

\section{Conclusions}

A smart city is an urban space in which a comfortable and safe environment is established using computer technology. In this paper, the components of a smart city were presented, and the perspectives and challenges for smart cities in Russia were reviewed. The components of a smart city include smart transport, smart communication, smart services, and a smart environment. These components can be subdivided into other components in turn. We proposed the following features for smart cities:

1. Smart Transport:

- Dynamic traffic assignment;

- Green energy transport;

- Smart public transport.

2. Smart Communication:

- Government portals;

- City problem trackers;

- Emergency notifications.

3. Smart Services:

- Smart healthcare;

- Smart education;

- Smart security.

4. Smart Environment:

- Smart buildings;

- Smart waste sorting;

- Charging stations;

- Interactivity.

The cities were reviewed in accordance with this structure. Smart transport is actively developing in many Russian cities. In most major cities in Russia, one can pay for a trip using a bank card. Furthermore, it is worth noting the trend toward green modes of transport, such as Moscow's electric buses.

Russian cities are quite developed in the field of smart communication. For example, there is a website operating all over Russia, "gosuslugi.ru", which meets a significant number of the goals of smart communication. During the COVID-19 pandemic, it became the main tool for communication between the government and the citizens. There is also an emergency notification system via SMS.

In other areas, Russian cities are less developed. For example, there is almost no infrastructure for separate garbage collection, nor are there many charging stations for electric vehicles. Besides, it is necessary to solve the issue of the compatibility of heterogeneous systems operating in the city.

One of the main problems hindering the development of smart cities in Russia is the lack of awareness of citizens about smart city opportunities. For example, the use of green 
technology will only be successful if civil responsibility and green technologies coexist in harmony.

To conclude, cities in Russia are actively developing, using information technologies to ensure maximum convenience of citizens. The prospects for smart cities in Russia are mainly related to the further development of the smart environment and the use of green technologies.

Author Contributions: Conceptualization, all authors; methodology, all authors; validation, all authors; investigation, A.Y.; resources, A.Y.; writing-original draft preparation, A.Y. and M.R.B.; writing-review and editing, all authors; visualization, all authors; supervision, M.R.B. and M.M.; project administration, M.R.B. All authors have read and agreed to the published version of the manuscript.

Funding: This research received no external funding.

Data Availability Statement: Not Applicable, the study does not report any data.

Acknowledgments: We thank Innopolis University for generously funding this endeavor.

Conflicts of Interest: The authors declare no conflict of interest.

\section{References}

1. Nations, U. World urbanization prospects: The 2014 revision, highlights. department of economic and social affairs. Popul. Div. U. N. 2014, 32. Available online: https:/ / population.un.org/wup/publications/files/wup2014-report.pdf (accessed on 22 September 2021).

2. Steinbrecher, J.; Salg, J.; Starzetz, J. The smart city as a solution to municipal challenges? KfW Res. Focus Econ. 2018. Available online: https:/ / www.kfw.de/PDF/Download-Center/Konzernthemen/Research/PDF-Dokumente-Fokus-Volkswirtschaft/ Fokus-englische-Dateien/Fokus-2018-EN/Fokus-Nr.-204-April-2018-Smart-Cities_EN.pdf (accessed on 22 September 2021).

3. Brundtland, G.H. Report of the World Commission on Environment and Development: "Our Common Future"; UN: New York, NY, USA, 1987.

4. Cocchia, A. Smart and digital city: A systematic literature review. Smart City 2014, 13-43. Available online: https://link.springer. com/chapter/10.1007/978-3-319-06160-3_2 (accessed on 22 September 2021).

5. Vishnivetskaya, A.; Alexandrova, E. "Smart city” concept. Implementation practice. In IOP Conference Series: Materials Science and Engineering; IOP Publishing: Paris, France, 2019; Volume 497, p. 012019. Available online: https://iopscience.iop.org/article/10.1 088/1757-899X/497/1/012019/pdf (accessed on 22 September 2021).

6. Carta, M. Creative City 3.0: Smart cities for the urban age. IX. Biennial of European Towns and Town Planners: Smart Planning for Europe's Gateway Cities. 2015. Available online: https:/ /iris.unipa.it/retrieve/handle/10447/70877/57354/230\%20Creative\% 20City\%203.0\%20(IX\%20Biennal,\%202012).pdf (accessed on 22 September 2021).

7. Vidiasova, L.; Cronemberger, F.; Vidiasov, E. Risk factors in smart city development in Russia: A survey. In Proceedings of the International Conference on Electronic Governance and Open Society: Challenges in Eurasia, St. Petersburg, Russia, 14-16 November 2018; Springer: Berlin/Heidelberg, Germany, 2018; pp. 26-37.

8. Stroev, P.; Reshetnikov, S. Trends and prospects for the development of "smart cities" in Russia. In Proceedings of the 3rd International Conference on Judicial, Administrative and Humanitarian Problems of State Structures and Economic Subjects (JAHP 2018), Domodedovo, Russia, 4-10 April 2018; Atlantis Press: Dordrecht, The Netherlands, 2018; pp. 71-76. Available online: https: / /www.atlantis-press.com/proceedings/jahp-18/25902078 (accessed on 22 September 2021).

9. Kupriyanovskiy, V.; Namiot, D.; Kupriyanovskiy, P. On standardization of Smart Cities, Internet of Things and Big Data. The considerations on the practical use in Russia. Int. J. Open Inf. Technol. 2016, 4, 34-40.

10. Mishchenko, V.; Lopatkin, D.; Chernyshov, V. Discussing the concept of smart city: Perspectives from Russia. In Proceedings of the MATEC Web of Conferences; EDP Sciences: Les Ulis, France, 2018; Volume 212, p. 04016. Available online: https: / / www.matecconferences.org/articles/matecconf/abs/2018/71/matecconf_icre2018_04016/matecconf_icre2018_04016.html (accessed on 22 September 2021).

11. Silva, B.N.; Khan, M.; Han, K. Towards sustainable smart cities: A review of trends, architectures, components, and open challenges in smart cities. Sustain. Cities Soc. 2018, 38, 697-713. [CrossRef]

12. Namiot, D.; Sneps-Sneppe, M. On the domestic standards for Smart Cities. Int. J. Open Inf. Technol. 2016, 4, 32-37.

13. BSI Standards. Available online: https://www.bsigroup.com/en-GB/smart-cities/Smart-Cities-Standards-and-Publication/ PAS-182-smart-cities-data-concept-model/ (accessed on 22 September 2021).

14. Digitalization Project Smart City. Available online: https://minstroyrf.gov.ru/trades/gorodskaya-sreda/proekt-tsifrovizatsiigorodskogo-khozyaystva-umnyy-gorod/ (accessed on 22 September 2021).

15. Fedele, R.; Praticò, F.G.; Pellicano, G. The prediction of road cracks through acoustic signature: Extended finite element modeling and experiments. J. Test. Eval. 2019, 49, 2942-2963. [CrossRef] 
16. Hasni, H.; Alavi, A.H.; Chatti, K.; Lajnef, N. A self-powered surface sensing approach for detection of bottom-up cracking in asphalt concrete pavements: Theoretical/numerical modeling. Construct. Build. Mater. 2017, 144, 728-746. [CrossRef]

17. Lenglet, C.; Blanc, J.; Dubroca, S. Smart road that warns its network manager when it begins cracking. IET Intell. Transp. Syst. 2017, 11, 152-157. [CrossRef]

18. Zygouras, N.; Zacheilas, N.; Kalogeraki, V.; Kinane, D.; Gunopulos, D. Insights on a Scalable and Dynamic Traffic Management System; EDBT: Edinburgh, UK, 2015; pp. 653-664. Available online: https://openproceedings.org/2015/conf/edbt/paper-342.pdf (accessed on 22 September 2021).

19. Saw, K.; Katti, B.; Joshi, G. Literature review of traffic assignment: Static and dynamic. Int. J. Transp. Eng. 2015, 2, 339-347.

20. Collotta, M.; Bello, L.L.; Pau, G. A novel approach for dynamic traffic lights management based on Wireless Sensor Networks and multiple fuzzy logic controllers. Expert Syst. Appl. 2015, 42, 5403-5415. [CrossRef]

21. Imbugwa, G.B.; Mazzara, M. Towards a Secure Smart Parking Solution for Business Entities. In Advanced Information Networking and Applications; Barolli, L., Woungang, I., Enokido, T., Eds.; Springer International Publishing: Cham, Switzerland, 2021; pp. $469-478$.

22. Imbugwa, G.; Manuel, M.; Distefano, S. Developing a Mobile Application Using Open Source Parking Management System on Etherium Smart Contracts. J. Phys. Conf. Ser. 2020, 1694, 012022. [CrossRef]

23. Wang, N.; Pan, H.; Zheng, W. Assessment of the incentives on electric vehicle promotion in China. Transp. Res. Part A Policy Pract. 2017, 101, 177-189. [CrossRef]

24. Nagy, V.; Horváth, B. The effects of autonomous buses to vehicle scheduling system. Procedia Comput. Sci. 2020, 170, 235-240. [CrossRef]

25. UK Tax Service. Available online: https://www.gov.uk/log-in-register-hmrc-online-services (accessed on 22 September 2021).

26. Sikder, M.F.; Halder, S.; Hasan, T.; Uddin, M.J.; Baowaly, M.K. Smart disaster notification system. In Proceedings of the 2017 4th International Conference on Advances in Electrical Engineering (ICAEE), Dhaka, Bangladesh, 28-30 September 2017; IEEE: Piscataway, NJ, USA, 2017; pp. 658-663.

27. Catarinucci, L.; De Donno, D.; Mainetti, L.; Palano, L.; Patrono, L.; Stefanizzi, M.L.; Tarricone, L. An IoT-aware architecture for smart healthcare systems. IEEE Internet Things J. 2015, 2, 515-526. [CrossRef]

28. Zhu, Z.T.; Yu, M.H.; Riezebos, P. A research framework of smart education. Smart Learn. Environ. 2016, 3, 1-17. [CrossRef]

29. Laufs, J.; Borrion, H.; Bradford, B. Security and the smart city: A systematic review. Sustain. Cities Soc. 2020, 55, 102023. [CrossRef]

30. Mazzara, M.; Afanasyev, I.; Sarangi, S.R.; Distefano, S.; Kumar, V.; Ahmad, M. A Reference Architecture for Smart and SoftwareDefined Buildings. In Proceedings of the 2019 IEEE International Conference on Smart Computing (SMARTCOMP), Washington, DC, USA, 12-15 June 2019; pp. 167-172. [CrossRef]

31. Zhang, L.P.; Zhu, Z.P. Can Smart Waste Bins Solve the Dilemma of Household Solid Waste Sorting in China? A Case Study of Fuzhou City. Pol. J. Environ. Stud. 2020, 29, 3943-3954. [CrossRef]

32. Voronezh, Smart Trafficl Lights. Available online: https://riavrn.ru/news/mer-voronezha-umnye-svetofory-snizili-vremyaproezda-perekrestkov-na-18/ (accessed on 22 September 2021).

33. Gosuslugi. Available online: https:/ / www.gosuslugi.ru/ (accessed on 22 September 2021).

34. Our City. Available online: https://gorod.mos.ru/(accessed on 22 September 2021).

35. People's Control. Available online: https://uslugi.tatarstan.ru/open-gov/all (accessed on 22 September 2021).

36. Mazzara, M.; Zhdanov, P.; Bahrami, M.R.; Aslam, H.; Imam, M.; Salem, H. Education after COVID-19. In Smart and Sustainable Technology for Resilient Cities and Communities-Advances in Sustainability Science and Technology; Springer: Berlin/Heidelberg, Germany, 2021.

37. SNiP 2.09.04-87. Available online: https://www.russiangost.com/p-18261-snip-20904-87.aspx (accessed on 22 September 2021).

38. Koubaa, A.; Aldawood, A.; Saeed, B.; Hadid, A.; Ahmed, M.; Saad, A.; Alkhouja, H.; Ammar, A.; Alkanhal, M. Smart Palm: An IoT framework for red palm weevil early detection. Agronomy 2020, 10, 987. [CrossRef]

39. O'Grady, M.; Langton, D.; O'Hare, G. Edge computing: A tractable model for smart agriculture? Artif. Intell. Agric. 2019, 3, 42-51. [CrossRef]

40. Mingaleva, Z.; Vukovic, N.; Volkova, I.; Salimova, T. Waste management in green and smart cities: A case study of Russia. Sustainability 2020, 12, 94. [CrossRef]

41. Brutti, A.; De Sabbata, P.; Frascella, A.; Gessa, N.; Ianniello, R.; Novelli, C.; Pizzuti, S.; Ponti, G. Smart city platform specification: A modular approach to achieve interoperability in smart cities. In The Internet of Things for Smart Urban Ecosystems; Springer: Berlin/Heidelberg, Germany, 2019; pp. 25-50. 